\title{
Research on the Relationship between Residents' Income Growth and Tourism Consumption: A Case Study of Wuhan
}

\author{
Ruoting Zhang \\ Jinan University, Guangzhou, China \\ Email: rtingz@126.com
}

How to cite this paper: Zhang, R. T. (2020). Research on the Relationship between Residents' Income Growth and Tourism Consumption: A Case Study of Wuhan. Modern Economy, 11, 763-775. https://doi.org/10.4236/me.2020.113056

Received: February 18, 2020

Accepted: March 27, 2020

Published: March 30, 2020

Copyright $\odot 2020$ by author(s) and Scientific Research Publishing Inc. This work is licensed under the Creative Commons Attribution International License (CC BY 4.0).

http://creativecommons.org/licenses/by/4.0/

\section{(c) (i) Open Access}

\begin{abstract}
With economic development, more and more people choose to travel. The income of residents is an important factor affecting tourism consumption. Taking Wuhan City as an example, this paper selects data from 1996 to 2015, uses Eviews software and co-integration analysis method to conduct an empirical analysis on residents' per capita disposable income and per capita tourism consumption expenditure, and quantitatively studies its dynamic relationship. The results show that there is a long-term stable relationship between the growth of residents' income and tourism consumption. The growth of residents' income has promoted tourism consumption expenditure. For every $1 \%$ increase in residents' disposable income, tourism consumption expenditure will increase by $1.1317 \%$. According to this result, it is possible to stimulate residents' tourism consumption by increasing the income level of residents and instituting some holiday welfare policies, thereby enabling China's tourism industry to develop better and promote economic growth.
\end{abstract}

\section{Keywords}

Residents, Disposable Income Per Capita, Tourism Consumption Per Capita, Cointegration Analysis

\section{Introduction}

With the development of the economy, tourism has become an increasingly popular activity. According to iiMedia Research data, the number of domestic tourists in 2018 was 5.54 billion, an increase of $10.8 \%$ over the same period last year; and domestic tourism revenue was 5.1 trillion yuan, an increase of $12.3 \%$ over the same period last year. From this data, we can see that the development of tourism is in full swing, showing a steady growth trend, and the tourism in- 
dustry has also become a new economic growth point. With the continuous improvement of people's quality of life, the demand for tourism will continue to expand, and the tourism industry will usher in greater development, thereby promoting economic growth. Therefore, it is necessary to analyze the factors that affect the tourism consumption of residents.

We know that there are many factors that affect tourism. Individual leisure time and tourism motivation will affect tourism consumption, but the most important factor is the income of residents. Because the residents' disposable income determines their spending power, and tourism consumption expenditure is directly affected by residents' disposable income. With the steady progress of reform and opening up, the per capita disposable income of Chinese residents has also continued to increase, and the per capita disposable income of national residents has increased year by year in the past five years, as shown in Figure 1. Among them, in 2017, the per capita disposable income of residents nationwide was 25,974 yuan, a nominal increase of $9.0 \%$ over the previous year. After deducting price factors, the actual increase was 7.3\%. In 2017, the per capita consumption expenditure of residents nationwide was 18,322 yuan, a nominal increase of $7.1 \%$ over the previous year. After deducting price factors, the actual increase was 5.4\%. Therefore, with the growth of China 's residents income and the rise of tourism as a lifestyle, analysis and prediction of the demand situation of the tourism market in the near future through past residents' income and tourism consumption data, and in-depth research on the relationship between residents' disposable income growth and tourism consumption, The relevant conclusions will provide an important basis for the forecast of the tourism market demand of tourism reception units, and it is of great significance to understand the tourism market and tourism consumption structure of our country and promote the development of China's tourism industry.

\section{Literature Review}

The relationship between residents' income and tourism consumption has been

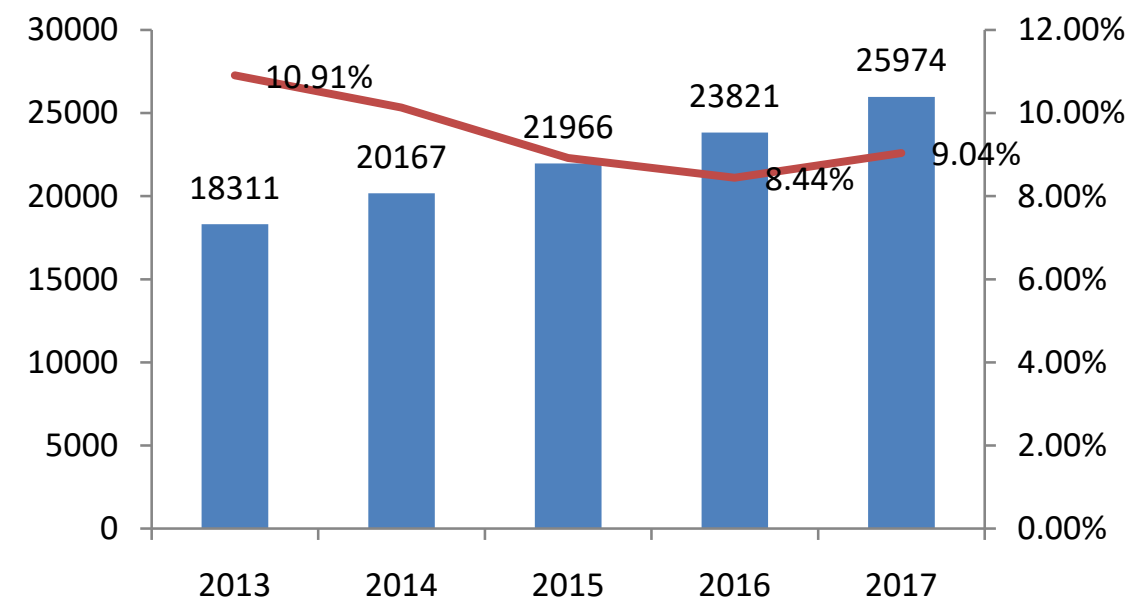

Figure 1. Per Capita disposable income of Chinese residents, 2013-2017. 
studied by many scholars. For example, Huang Cancan (2016) obtained the initial income distribution by selecting the initial distribution wage rate, the Gini coefficient of urban residents, and the proportion of tourism consumption of each income class. The aggregate impact has a greater impact on tourism consumption of the middle-income class, and the structural impact of initial income distribution has a greater impact on tourism consumption of the high-income class; Fang Jing (2015) used the knowledge of econometrics to establish a univariate linear model, test autocorrelation, modified autocorrelation, and heteroscedasticity, and concluded that rural residents' per capita net income has a strong linear correlation with per capita tourism consumption expenditure; Yao Lifen, Long Ruyin, Li Qingchen (2010) used co-integration theory, error trimming model, and Granger causality test to conduct an empirical study on the relationship between domestic tourism consumption and residents' income levels in China, and the income levels of urban and rural residents The relationship between tourism consumption and tourism consumption is analyzed. It is concluded that there is a long-term equilibrium relationship between tourism consumption and residents' income. The conclusion is that rural residents' income promotes tourism consumption more clearly than urban residents; Liu Jia (2007) believes that tourism consumption has general characteristics of consumption, and there is a close correlation between tourism consumption and disposable income and prices: tourism consumption is positively related to disposable income and negatively related to prices; Su Fajin (2012) compared the relationship between urban and rural residents' tourism consumption and income, showing that current income and lasting income are Granger reasons that affect the changes in tourism consumption expenditure of urban and rural residents; Sun Gennian and Xue Jia (2009a, 2009b) used the Cobb-Douglas production function and logarithmic straight-line model to quantitatively analyze the changes in domestic tourist flow and travel rate of urban and rural residents driven by per capita income. Tourism provides a scientific basis and proposes that personal disposable income is the basic factor affecting and restricting residents' domestic tourism demand; Liu $\mathrm{Na}$ (2017) research found that residents' discretionary income status can be used as an important basis for predicting the local residents' recent tourism consumption capacity; Huang Lianyun (2017) studied the tourism consumption linearity of Chengdu and found that increasing the per capita disposable income of rural residents is more effective than increasing the per capita disposable income of urban residents. The rural consumer tourism consumption market will become the next driving force for the development of tourism in Chengdu (Huang, 2017).

Taking Wuhan as an example, this paper selects Wuhan's residents' disposable income and tourism consumption expenditure data for quantitative analysis from 2001 to 2015, in-depth studies the relationship between residents' income growth and tourism consumption, and through the study of the data, proposes the corresponding Measures to promote the development of China's tourism industry, thereby promoting economic development. 


\section{Data Processing and Model Building}

\subsection{Data Processing}

Taking into account the actual situation and the availability of data, this article chooses to analyze the per capita disposable income and per capita tourism consumption expenditure of Wuhan residents from 1996 to 2015. The time series of per capita disposable income and tourism consumption of residents was obtained from Wuhan Statistical Yearbook and China Tourism Statistical Yearbook from 1996 to 2015. In the process of Eviews data processing and model building, in order to eliminate heteroscedasticity in time series and changes in price index, the per capita disposable income and per capita consumption were taken as the logarithm and recorded as LNINCOME and LNCOST.

\subsection{Correlation Analysis of Data}

First, we can look at the scatter plots of the two sequences of LNINCOME and LNCOST (shown in Figure 2). It can be seen from the scatter plot that the degree of fitting between the two is good, and there should be a strong correlation.

To further determine the correlation between the two sequences, a correlation analysis is also required. We first use Eviews to perform correlation analysis on the two groups of variables, and the results are shown in Figure 3. According to the results in Figure 3, it can be seen that the correlation coefficient between per capita disposable income and per capita tourism consumption is 0.9571 , a small difference from 1, indicating that there is a clear correlation between the two. It is inferred that the per capita tourism consumption of residents will increase

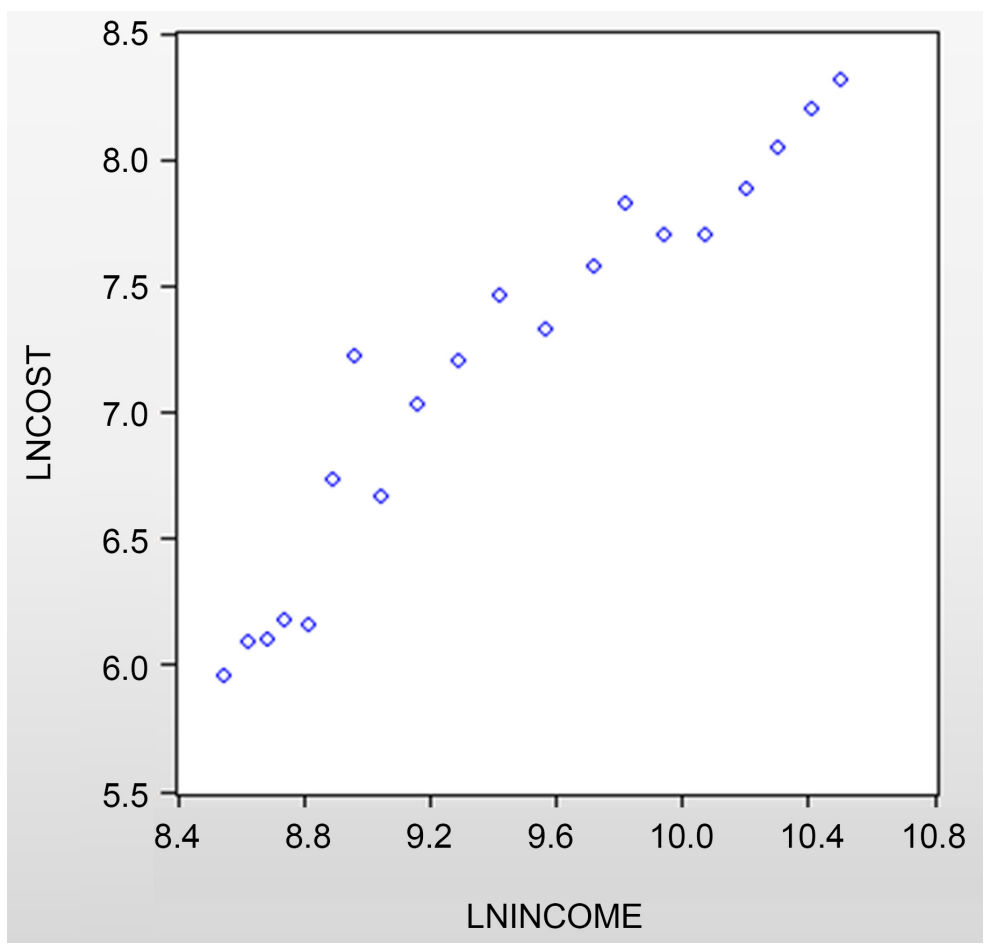

Figure 2. Correlation between LNINCOME and LNCOST. 


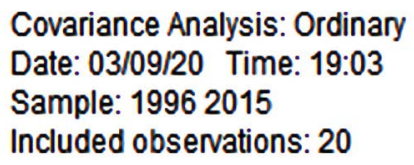

\begin{tabular}{c|rc}
\hline \hline Correlation & LNINCOME & LNCOST \\
\hline LNINCOME & 1.000000 & \\
LNCOST & 0.957069 & 1.000000 \\
\hline \hline
\end{tabular}

Figure 3. Correlation coefficient between residents' per capita disposable income and per capita tourism consumption.

with the growth of per capita disposable income of residents and per capita net income of rural residents.

\subsection{Model Building}

1) Based on the above data analysis, we can establish a regression model that reflects the relationship between residents' income growth and tourism consumption:

$$
\mathrm{LNCOST}=a+b \mathrm{LNINCOME}+u
$$

2) In formula (1), LNCOST represents the tourism consumption level of $\mathrm{Wu}$ han residents, LNINCOME represents the income level of Wuhan residents, a and $b$ are parameters, and $\mathrm{u}$ is a random disturbance term. The data analysis in this paper is completed on the basis of Eviews 7.

\section{Regression Results and Analysis}

\subsection{Stationary Analysis}

The premise of co-integration analysis of the two time series of LNINCOME and LNCOST is that the two variables must be stationary, that is, the variables do not fluctuate sharply over time. Therefore, we perform stationarity analysis on two sets of sequences and use Eviews to obtain the timing diagrams of the two sequences (Figure 4). It can be seen from Figure 4 that both LNINCOME and LNCOST are affected by time, and these two sets of sequences do not have stationarity. Therefore, we will observe the stationarity using a differential method.

Firstly, the two sets of data are subjected to first-order difference and recorded as DLNINCOME and DLNCOST. The first-order difference timing diagram obtained by Eviews is shown in FIG. As can be seen from Figure 5, the two sequences of DLNINCOME and DLNCOST have plateau.

Next, we can use the ADF unit root test to more accurately determine the stability of the sequence, and use Eviews to perform the ADF unit root test. From the results of Figure 6 and Figure 7, we can see that the P value of the ADF test in Figure 6 is 0.9995, which is much greater than 5\%. The non-stationary null hypothesis is accepted, that is, LNINCOME and LNCOST are significant in both sequences at $5 \%$. The horizontal time series is a non-stationary time series diagram. After the first-order difference, the ADF test result in Figure 7 shows that 


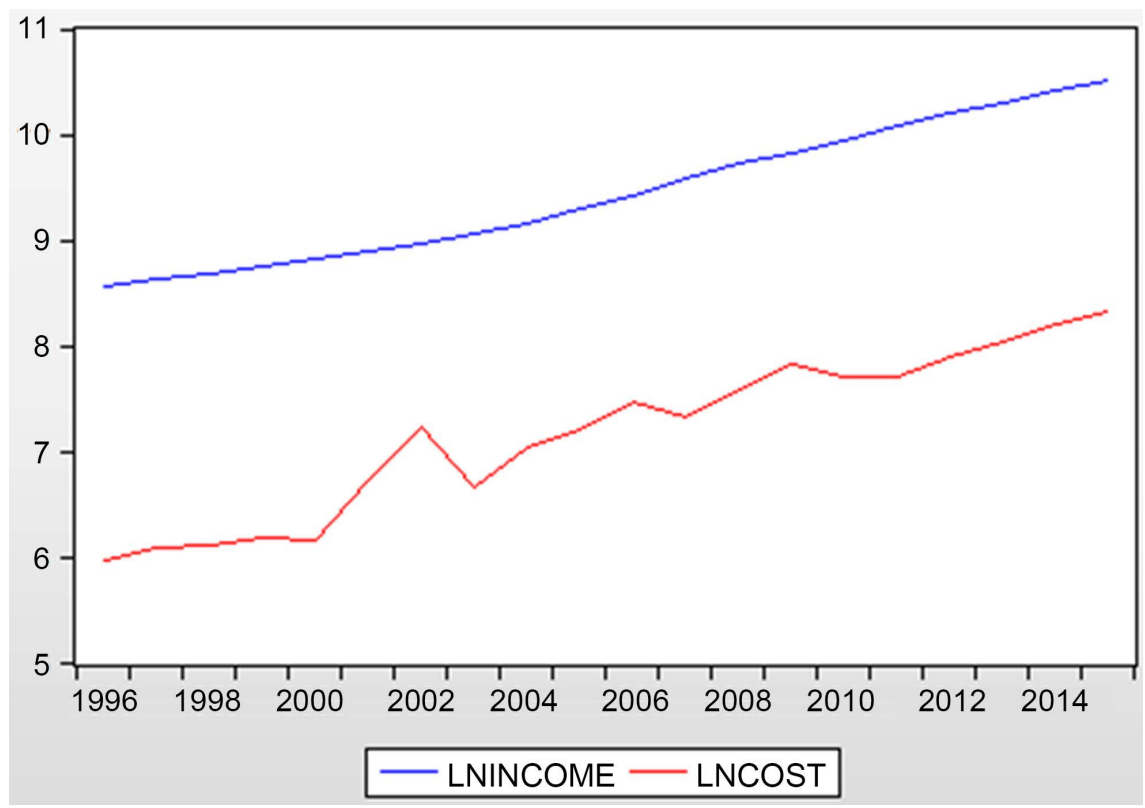

Figure 4. Timing chart of LNINCOME and LNCOST.

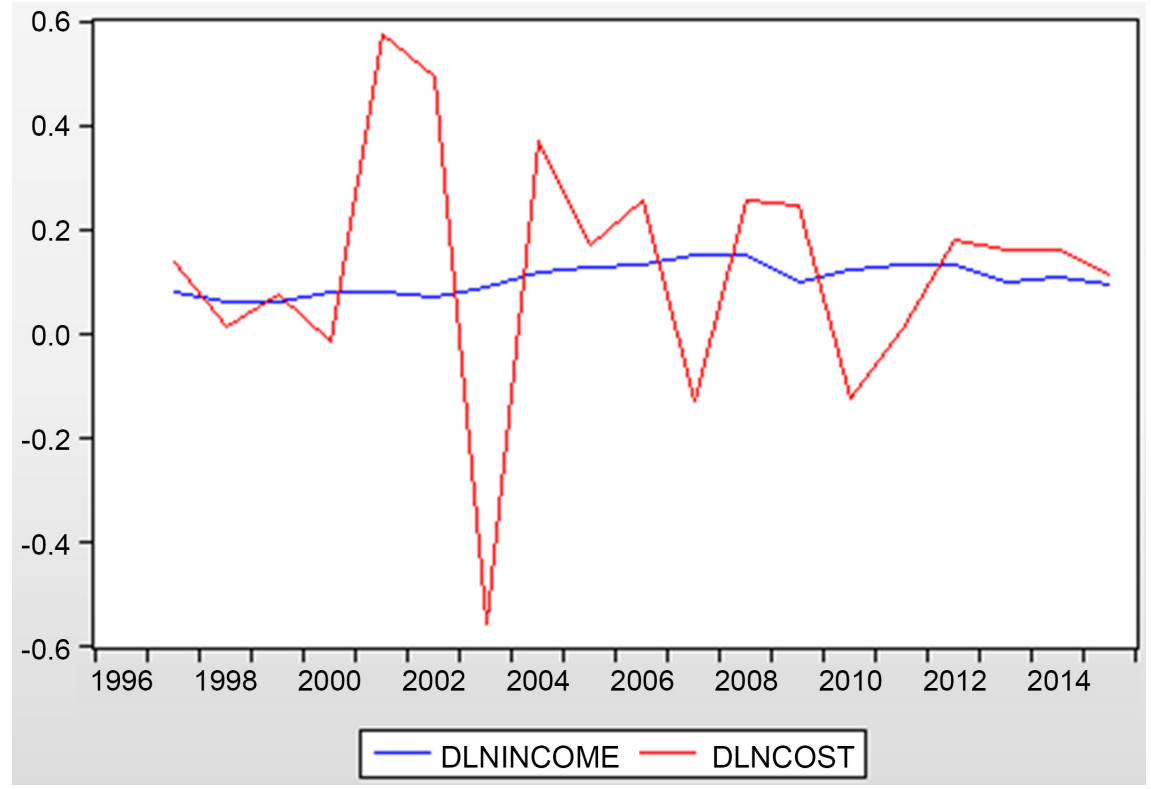

Figure 5. First-order differential timing diagram of LNINCOME and LNCOST.

the $\mathrm{P}$ value is 0.0012 , which is less than $5 \%$. The null hypothesis is rejected, so the unit root test after the first-order difference of LNINCOME and LNCOST. The result is stable, indicating that there is a unit root for LNINCOME and LNCOST, which satisfies the premise of co-integration test. Co-integration test can be performed. This paper uses the E-G two-step co-integration model.

\subsection{Cointegration Test}

1) OLS Regression Analysis

According to the previously established model (1), we use the least squares 
Null Hypothesis: Unit root (individual unit root process)

Series: LNINCOME, LNCOST

Date: 03/09/20 Time: 17:47

Sample: 19962015

Exogenous variables: None

Automatic selection of maximum lags

Automatic lag length selection based on SIC: 1 to 2

Total number of observations: 35

Cross-sections included: 2

\begin{tabular}{lcc}
\hline \hline Method & Statistic & Prob. $^{\star \star}$ \\
\hline ADF - Fisher Chi-square & 0.06409 & 0.9995 \\
ADF - Choi Z-stat & 3.45870 & 0.9997 \\
\hline \hline
\end{tabular}

** Probabilities for Fisher tests are computed using an asymptotic Chi -square distribution. All other tests assume asymptotic normality.

Intermediate ADF test results GROUP02

\begin{tabular}{ccccc}
\hline \hline & & & & \\
Series & Prob. & Lag & Max Lag & Obs \\
\hline LNINCOME & 0.9697 & 1 & 4 & 18 \\
LNCOST & 0.9987 & 2 & 4 & 17 \\
\hline \hline
\end{tabular}

Figure 6. ADF unit root test results of LNINCOME and LNCOST.

Null Hypothesis: Unit root (individual unit root process)

Series: LNINCOME, LNCOST

Date: 03/09/20 Time: $17: 49$

Sample: 19962015

Exogenous variables: None

Automatic selection of maximum lags

Automatic lag length selection based on SIC: 0

Total (balanced) observations: 36

Cross-sections included: 2

\begin{tabular}{lcc}
\hline \hline Method & Statistic & Prob.** \\
\hline ADF - Fisher Chi-square & 18.1473 & 0.0012 \\
ADF - Choi Z-stat & -2.38278 & 0.0086 \\
\hline \hline
\end{tabular}

** Probabilities for Fisher tests are computed using an asymptotic Chi -square distribution. All other tests assume asymptotic normality.

Intermediate ADF test results D(GROUP02)

\begin{tabular}{ccccc}
\hline \hline & & & & \\
Series & Prob. & Lag & Max Lag & Obs \\
\hline D(LNINCOME) & 0.5664 & 0 & 4 & 18 \\
D(LNCOST) & 0.0002 & 0 & 4 & 18 \\
\hline \hline
\end{tabular}

Figure 7. ADF unit root test results for LNINCOME and LNCOST.

method (OLS) to perform regression analysis on the two series of LNINCOME and LNCOST, and use Eviews software to estimate the parameters in the model. The results obtained are shown in Figure 8. From the regression analysis results in Figure 8, we can get the regression model. 


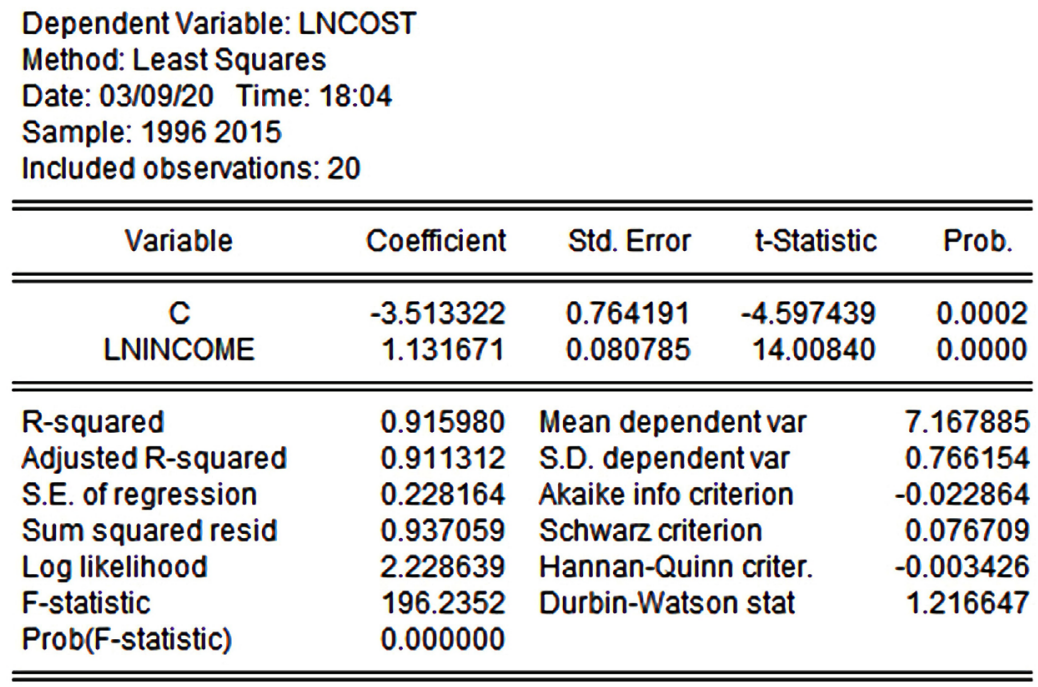

Figure 8. Results of regression analysis.

$$
\begin{gathered}
\text { LNCOST }=-3.5133+1.1317 \text { LNINCOME }+u \\
(-4.5974)(14.0084) \\
\mathrm{R}^{2}=0.9159 \mathrm{DW}=1.2166 \mathrm{~F}=196.2352
\end{gathered}
$$

According to the $\mathrm{P}$ value of the constant term of 0.0002 and the $\mathrm{P}$ value of the LNINCOME estimated parameter of 0.0000 , it can be seen that both are less than 0.05 , that is, the estimation of the regression coefficient has passed the significance level test of $5 \%$, and the regression equation has a better fit.

The estimated coefficient before LNINCOME is 1.1317 , which is greater than 0 , indicating that there is a significant positive correlation between residents' income and tourism consumption. Verified the previous conjecture.

2) Residual Test

In the model we obtained in the previous step, there are residual terms. The estimation of the regression equation must meet the stationarity of the residual sequence to explain the long-term relationship between LNINCOME and LNCOST in the estimated cointegration equation. Therefore, after we get the regression equation, we need to perform a stationary analysis on its residual term. Here we still use the ADF unit root test of Eviews, and the result is shown in Figure 9.

According to the results of the residual test in Figure 9, we can see that at the levels of $1 \%, 5 \%$, and $10 \%$, the $t$ values of the residuals are $-3.886751,-3.052169$, -2.666593 , and the $P$ value is 0.0023 , which is less than 0.05 , which indicates that the residual sequence is stable at a significant level of $5 \%$. Therefore, the co-integration analysis of LNINCOME and LNCOST is meaningful, which indicates that there is a long-term stable relationship between the growth of residents' income and tourism consumption.

Combining the analysis results of Figure 8 and Figure 9, we can conclude that the regression coefficient estimation in the model (2) has a higher degree of fit, and the model has a stronger degree of interpretation. 


\section{Null Hypothesis: D(RESID01) has a unit root Exogenous: Constant Lag Length: 1 (Automatic - based on SIC, maxlag=4)}

\section{*Mackinnon (1996) one-sided p-values. \\ Warning: Probabilities and critical values calculated for 20 observations and may not be accurate for a sample size of 17}

Figure 9. ADF test results of residuals.

The regression coefficient in the model indicates the elasticity between residents' income growth and tourism consumption. Therefore, we conclude from the model results that the per capita tourism consumption expenditure of residents increases by $1.1317 \%$ for each $1 \%$ increase in the disposable income of residents.

\subsection{Granger Causality Test}

1) In the above, we conducted a cointegration test on the relationship between residents' per capita disposable income and per capita tourism consumption expenditure, and concluded that a long-term equilibrium relationship exists between the two. But whether the relationship between the two is mutual influence or unilateral influence requires further discussion.

2) Granger causality test is used to analyze one variable is the cause of a change in another. We use Eviews to perform Granger causality tests on two groups of variables, LNINCOME and LNCOST, and the results are shown in Figure 10.

3) According to the Granger cause-effect test result in Figure 10, we can see that when the first-order lag, LNCOST is not LNINCOME. The corresponding $\mathrm{P}$ value is 0.1207 , and the $\mathrm{P}$ value is greater than 0.05 . Therefore, the null hypothesis is accepted: LNCOST is not LNINCOME Granger Reason. The LNINCME is not a Granger reason for LNCOST, the corresponding P value is 0.0305 , and the $P$ value is less than 5\%, so the null hypothesis is rejected at a significant level of 5\%: LNINCOME is the Granger reason for LNCOST, that is, the increase in residents' per capita income will cause residents' per capita tourism spending. It shows that the growth of residents' income can promote the tourism consumption of residents, but the growth of residents' tourism consumption will not cause the growth of residents' income. This is a one-way causality.

Combining the results of the regression model and the Granger causality test we can conclude: Resident income is an important factor affecting residents' tourism consumption, Growth in residents' income boosts spending on tourism, 


\begin{tabular}{|c|c|c|c|}
\hline $\begin{array}{l}\text { Pairwise Granger Causality Tests } \\
\text { Date: 03/09/20 Time: } 18: 13 \\
\text { Sample: } 19962015 \\
\text { Lags: } 1\end{array}$ & & & \\
\hline Null Hypothesis: & Obs & F-Statistic & Prob. \\
\hline $\begin{array}{l}\text { LNCOST does not Granger Cause LNINCOME } \\
\text { LNINCOME does not Granger Cause LNCOST }\end{array}$ & 19 & $\begin{array}{l}2.68656 \\
5.62988\end{array}$ & $\begin{array}{l}0.1207 \\
0.0305\end{array}$ \\
\hline
\end{tabular}

Figure 10. Granger causality test results.

The degree of promotion is that for every $1 \%$ increase in residents' income, the tourism consumption expenditure of residents will increase by $1.1317 \%$.

\subsection{Analysis of the Relationship between Disposable Income and Tourism Consumption}

Among the factors affecting tourism consumption, the disposable income of residents plays a key role. The level of income determines the level of consumption and the degree of satisfaction of demand, thus determining the change in consumption structure (Tian, 2002). Higher residents' income means more ability to pay for tourism; residents' disposable income provides economic support for tourism consumption. Because during the tour, tourists need to pay a certain amount of food and accommodation, the choice of transportation mode and choice of residence throughout the entire travel process, the travel mode has a certain relationship with the economic capacity of tourists, that is, with the disposable income of residents. Therefore, residents' disposable income is an important indicator affecting tourism consumption.

Residents with higher disposable income have more spare money for leisure activities; there are even paid vacation benefits. But the low disposable income of residents means less leisure time, weak leisure awareness, and difficulty in bearing certain travel expenses. Therefore, the demand for tourism with higher disposable income of residents is higher. The increase in tourism demand has led to an increase in tourism consumption expenditure, which also explains why higher residents' income promotes more tourism consumption.

\section{Research Conclusions and Recommendations}

Based on an empirical analysis of the relationship between Wuhan residents' per capita disposable income and residents' per capita consumption expenditure, this paper draws the following conclusions: There is a long-term stable relationship between the growth of residents' income and the tourism consumption of residents. The growth of residents' income is an important factor affecting tourism consumption expenditure, and this impact is one-way, the increase of residents' income will promote the growth of tourism consumption, and the opposite is not true. The quantitative relationship between residents' income is: for every $1 \%$ increase in residents' income, tourism consumption expenditure will increase by $1.1317 \%$. 
This article draws the above conclusions by exploring the relationship between Wuhan residents' disposable income growth and tourism consumption, which can infer to some extent the impact of national residents' income growth on tourism consumption, it can also predict future consumption trends and provide a policy basis for promoting the development of China's tourism industry. Based on the above research conclusions, this article makes several suggestions for the development of China's tourism industry:

- Since the growth of residents' income has a driving effect on tourism consumption, it is necessary to increase the disposable income of residents. By adjusting the income distribution structure, the gap between the rich and the poor has been reduced, the number of low-income groups has been reduced, and the middle-class group has grown, thereby increasing the number of tourists. The threshold should be raised to reduce national fiscal revenue and increase residents' income. Furthermore, by improving the social security system, subsidizing low-income people and solving their basic living problems, this will reduce their concerns about savings and housing, which will increase their disposable income.

- Formulate preferential policies for holiday activities. Since most of the residents choose to travel in their spare time, it is necessary for the country to introduce preferential policies for travel on holidays such as the "May 1st" and "11th" Golden Week. For example, during the festival, bridge tolls and road tolls are free, which will encourage residents who drive by themselves to a certain extent. This will give residents a little preferential treatment, which will greatly promote their tourism consumption. Moreover, like round-trip airfare discounts, package activities, full reduction activities, etc. launched by travel companies, let everyone feel that travel is no longer a luxury, so that everyone can spend money comfortably, so that they are more willing to travel.

- Local conditions to stimulate tourism consumption of local residents. Local governments can encourage more diverse management of local tourism companies. Introduce policies that are beneficial to local residents and the development of the local tourism industry, those living in mountains live off the mountains and those living near waters live off the waters. Develop a good scenic area and increase the protection of the developed scenic area, so that more people do not have to wait for long holidays to travel far away, and can enjoy local tourism on weekends.

- Develop welfare policies. The government can start with the system to allow residents more leisure time to travel. For example, the double vacation system and paid vacation system allow office workers to relieve their work pressure and let go of tourism. Enterprises can also formulate some systems, such as work performance and work performance to a certain degree, can reward tourism in a certain place, on the one hand, not to lose performance, on the other hand, increase the travel time of employees. 
- Technology and Services to Improve Tourism. Travel services in the Internet era are more conducted online. Therefore, good technology determines the convenience and speed of ticket purchase and hotel check-in. To a certain extent, it makes everyone feel that going out is an easy task. This will greatly promote people's desire to travel and also save more. Time to play more. The service of tourist attractions is also something that companies need to pay attention to. Good services and people's acceptable prices will attract more people to travel. The improvement of cost performance requires companies to strengthen management and grasp the psychology of consumers, so that companies will increase their income. So as to improve better services, a virtuous circle promotes the development of tourism enterprises.

- Strengthening the management of tourism. Shopping chaos with group purchases, commitments that are inconsistent with facts, price hikes on the ground, and other tourist chaos have repeatedly occurred in the past. Therefore, the tourism bureau must strengthen management, safeguard consumer rights, and prevent the phenomenon of disorderly shopping and opaque ticket purchase. Some travel agencies that harm the interests of consumers are severely punished, and some good service travel agencies are encouraged to issue awards. The tourism bureau can also give correct instructions and help when consumers are in trouble, so that the tourism industry can develop healthier.

\section{Contributions and Shortcomings}

The contribution of this article is to enhance the prediction of tourism consumption trends and the overall development of the tourism economy, and to be able to more accurately understand the tourism consumption needs of Chinese residents from the perspective of income contribution, so as to enhance residents' happiness and satisfy the people through the development of the tourism industry The good life needs to provide countermeasures. The related conclusions will provide an important basis for tourism reception units to provide tourism market demand forecasts, and have important practical significance for understanding China's tourism market, tourism consumption structure, and promoting the development of China's tourism industry.

The inadequacy of this article is that it only discusses the impact of overall household income on tourism consumption, and does not conduct heterogeneous analysis, that is, household income includes wage income, property income, operating income, transfer income, etc. The impact of tourism consumption may be different. If the impact is classified and discussed, the conclusions drawn are more relevant to the policy proposal.

\section{Conflicts of Interest}

The authors declare no conflicts of interest regarding the publication of this paper. 


\section{References}

Fang, J. (2015). A Study on the Relationship between Tourism Consumption and Income of Rural Residents in China. Local Economy, 477-479.

Huang, C. C. (2016). Research on the Impact of Initial Income Distribution on Tourism Consumption of Chinese Residents. Journal of Chongqing University of Arts and Sciences, No. 3, 152-157.

Huang, L. Y. (2017). Analysis of Chengdu Residents' Domestic Tourism Consumption and Disposable Income Growth. Cooperative Economy and Science and Technology, No. 14, 77-80.

Liu, J. (2007). Econometric Analysis of Tourism Consumption of Urban Residents in China. Business Culture.

Liu, N. (2017). Research on the Relationship between Chinese Residents' Income and Tourism Consumption. Contemporary Economy, No. 33, 68-69.

$\mathrm{Su}$, F. J. (2012). A Comparative Study on the Relationship between Tourism Consumption and Income of Urban and Rural Residents in China. Journal of Jinan: Philosophy and Social Science Edition, No. 10, 139-145.

Sun, G. N., \& Xue, J. (2009a). Forecast of Domestic Tourism Demand of Chinese Urban and Rural Residents. Urban Issues, No. 1, 68-72.

Sun, G. N., \& Xue, J. (2009b). Research on Income-Driven Domestic Tourism Model of Residents. Business Research, No. 5, 13-16.

Tian, L. (2002). Tourism Economics. Beijing: Higher Education Press.

Yao, L. F., Long, R. Y., \& Li, Q. C. (2010). A Cointegration Analysis of the Relationship between Chinese Residents' Income and Tourism Consumption. Geography and Geographic Information Science, No. 11, 92-95. 